\title{
Profile of Random Blood Glucose of Children Seen at the Children Outpatient Department of Ekiti State University Teaching Hospital, Ado-Ekiti, Nigeria
}

\author{
Oluwayemi I0 ${ }^{1,2 *}$, Ogundare EO ${ }^{1,2}$ Ajite $\mathrm{AB}^{1,2}$ and Raimi $\mathrm{TH}^{3}$ \\ ${ }^{1}$ Department of Pediatrics, Ekiti State University, Nigeria \\ ${ }^{2}$ Deparment of Pediatrics, Ekiti State University Teaching Hospital, Nigeria \\ ${ }^{3}$ Deparment of Medicine, Ekiti State University \& Ekiti State University Teaching Hospital, Nigeria
}

*Corresponding author: Isaac Oludare Oluwayemi, Department of Paediatrics, Faculty of Clinical Sciences, College of Medicine, Ekiti State University, Ado-Ekiti, Nigeria

Submission: 眥February 02, 2018; Published: 望 February 19, 2018

\begin{abstract}
Objective: To describe the pattern of random blood glucose levels of children presenting at the children outpatient department of the Ekiti State University Teaching Hospital (EKSUTH), Ado-Ekiti

Method: Consecutive children aged 15years and below who presented at the Children Out-Patient Department (COPD) of EKSUTH between January 2015 and May 2015 whose parent or guardian gave consent to participate in the study had their random blood glucose (RBG) done and the result analyzed with statistical package for social science (SPSS).

Results: Six hundred and five children (366 males and 239 females) were studied, $70.4 \%$ of them were aged $\leq 5 y e a r s$ at the time of the study. RBG of the studied children ranged from 1.2 to $25.0 \mathrm{mmol} / \mathrm{L}$. The mean RBG was $6.42 \pm 0.75$. Majority ( $86.8 \%$ ) of the patients were euglycaemic, $12.9 \%$ were hyperglycemic while $0.3 \%$ were hypoglycemic. Of the 525 patients who were euglycemic $93(17.7 \%)$ were admitted compared to $38(48.7 \%)$ of the 78 patients with hyperglycemia; the difference was statistically significant $\left(x^{2}=51.083 ; p=0.000\right)$. Ninety five $(15.7 \%)$ of the 605 patients drank fizzy drinks within 2 hours before RBG check and none (0\%) of these had hypoglycemia; 76(80\%) were euglycaemic; $14(14.7 \%)$ were hyperglycemic and 5(5.3\%) had profound hyperglycemia compared to $2(0.4 \%), 449(88.0 \%), 52(10.2 \%)$ and $7(1.4 \%)$ who had hypoglycemia, euglycaemia, hyperglycemia and profound hyperglycemia respectively of the remaining 510 (84.3\%) patients who did not drink any fizzy drink. The difference was statistically significant $\left({ }^{2}=8.594 ; p=0.035\right)$. Patients with duration of illness less than 7 days before presentation and those with dysglycaemia were more likely to be admitted for further treatment ( $p=0.001$ and $0.000 ; \beta$ coefficient $=0.399$ and 0.277 respectively).
\end{abstract}

Conclusion: Transient hyperglycaemia is relatively common among patients seen in children outpatient department. Duration of illness less than 7 days and dysglycaemia were predictive of patients that were.

Keywords: Random Blood Glucose; Children; Out-patient; Hyperglycemia; Hypoglycemia; Euglycaemia, Dysglycaemia

\section{Introduction}

Disorders of glucose metabolism often accompanies acute illnesses [1,2]. It has also been postulated that hyperglycemia during acute illness may put affected patients at a higher risk of developing type 2 diabetes mellitus later in life [3,4]. Hyperglycemia during acute illness may be caused by mediators of stress and inflammation [3]. Hyperglycemia is commoner in severely ill patients but not all critically ill patients develop Hyperglycemia. Hyperglycemia can also occur in patients with mild illness who did not previously have history of diabetes [1-4]. Hypoglycemia has also been documented in ill Pediatric patients [2]. Hypoglycemia may result from reduced oral intake during illness, rapid utilization of glucose by plasmodium falciparum in severe malaria and druginduced hyperinsulinism where quinine is used for treatment of severe malaria $[2,5,6]$. Failure to identify the disorder of glucose metabolism associated with acute illnesses can have short and long term adverse effect on patients [2-4]. Studies on the pattern of random blood glucose among ill children in Pediatric Out-Patient are very scarce; most published studies within and outside Africa [1-12] were conducted on critically ill patients in emergency wards or intensive care units hence the need for this study to validate the disorder of glucose metabolism among ill children seen in Pediatrics Out-Patient Department with a view to proffering practical recommendations for early detection and management 
of disorders of glucose metabolism associated with acute illnesses in children managed on out-patient basis. Report on the predictors of Paediatrics admission in our environment is scanty. Specifically, whether RBG at presentation in Paediatrics out-patients predicts those who will be admitted is unknown in our environment. Our hypothesis is that RBG level at presentation will determine those who will be admitted.

\section{Method}

Consecutive non diabetic children aged 15years and below who presented at the Children Out-Patient Department (COPD) of EKSUTH between January 2015 and May 2015, whose parent or guardian gave consent to participate in the study had their RBG done using capillary blood sampling on a portable glucometer. Demographic and clinical data were entered into a questionnaire and analyzed with statistical package for social sciences (SPSS) version 22. Categorical data were compared with Chi square and the level of significance was set at $<0.05$. Logistic regression was done to determine factors that were predictive of outcome i.e. whether or not patient will be admitted. The dependent variable was outcome; while the independent variables were sex, age, RBG, and duration of illness.

\section{Results}

Table 1: Age group of Children seen at COPD, EKSUTH.

\begin{tabular}{|c|c|c|}
\hline Age Group (yrs) & Frequency & Percent (\%) \\
\hline $0-5$ & 426 & 70.4 \\
\hline$>5-10$ & 96 & 15.9 \\
\hline$>10$ & 83 & 13.7 \\
\hline Total & 605 & 100 \\
\hline
\end{tabular}

Table 2: Pattern of RBG among Children seen in COPD of EKSUTH.

\begin{tabular}{|c|c|c|}
\hline RBG Grading & Frequency & Percent (\%) \\
\hline$<2.8 \mathrm{mmol} / \mathrm{L}$ (Hypoglycaemia) & 2 & 0.3 \\
\hline 2.8 to $<7.8 \mathrm{mmol} / \mathrm{L}$ (Euglycaemia) & 525 & 86.8 \\
\hline 7.8 to $11.1 \mathrm{mmol} / \mathrm{L}$ (Hyperglycaemia) & 66 & 10.9 \\
\hline$>11.1 \mathrm{mmol} / \mathrm{L}$ (Profound hyperglycaemia) & 12 & 2 \\
\hline Total & 605 & 100 \\
\hline
\end{tabular}

A total of 605 children aged 15years and below were enrolled for the study. Their mean age was $4.25 \pm 0.17$ years. There were 366 males and 239 females giving male: female ratio of 1.5:1. Majority, $426(70.4 \%)$ of these children were in the age group five years and below (Table 1). The duration of illness before presentation ranged from few hours to 365 days. 95(15.7\%) of the studied children have been given fizzy drink within 2 hours before the random blood glucose (RBG) test. The RBG of the studied children ranged from 1.2 to $25.0 \mathrm{mmol} / \mathrm{L}$. The mean RBG was $6.42 \pm 0.75$. Majority $(86.8 \%)$ of the patients were euglycaemic, $0.3 \%$ were hypoglycemic while $12.9 \%$ were hyperglycemic (Table 2). None of the $12(2 \%)$ patients who had profound Hyperglycemia in the diabetic range was confirmed to have diabetes; the result of their follow-up fasting blood glucose was within normal limit.

Of the 525 patients who were euglycemic 93(17.7\%) were admitted compared to $38(48.7 \%)$ of the 78 patients with Hyperglycemia; the difference was statistically significant $\left(x^{2}=\right.$ 51.083; $\mathrm{p}=0.000)$. Of the 605 studied children $443(73.2 \%)$ were treated and followed up on outpatient basis; $132(21.8 \%)$ were admitted into children emergency ward while 30(5\%) were referred to other specialties like Surgery. The four commonest presentation at children outpatient department of EKSUTH were respiratory tract infection (23.5\%), malaria (22\%), gastroenteritis (12.4\%) and skin rashes (9.4\%) as shown in Table 3.

Table 3: Pattern of Presentations at Children Out-Patient Department.

\begin{tabular}{|c|c|c|}
\hline Diagnosis & Frequency & Percent \\
\hline Malaria & 133 & 22 \\
\hline $\begin{array}{c}\text { Respiratory tract } \\
\text { infection }\end{array}$ & 142 & 23.5 \\
\hline gastroenteritis & 75 & 12.4 \\
\hline surgical & 47 & 7.8 \\
\hline skin rashes & 57 & 9.4 \\
\hline abdominal discomfort & 32 & 5.3 \\
\hline malnutrition & 5 & 0.8 \\
\hline others & 114 & 18.8 \\
\hline Total & 605 & 100 \\
\hline
\end{tabular}

Comparing the blood glucose value of those who had fizzy drinks and those who did not within 2hours of presentation: of the 95 patients who drank fizzy drinks within 2hours before RBG check, none (0\%) had hypoglycemia; 76(80\%) were euglycaemic; $14(14.7 \%)$ were hyperglycemic and $5(5.3 \%)$ had profound Hyperglycemia compared to $2(0.4 \%), 449(88.0 \%), 52(10.2 \%)$ and $7(1.4 \%)$ who had hypoglycemia, euglycaemia, Hyperglycemia and profound Hyperglycemia respectively of the 510 patients who did not drink any fizzy drink within 2hours before RBG check (Table 4). The difference was statistically significant $\left(x^{2}=8.594 ; p=0.035\right)$.

Table 4: Cross tabulation of RBG of children who ingested fizzy drink against those who did not $\left(x^{2}=8.594 ; p=0.035\right)$.

\begin{tabular}{|c|c|c|c|c|c|c|}
\hline \multicolumn{7}{|c|}{ Random Blood Glucose Grading (mmol/L) } \\
\hline & & $<\mathbf{2 . 8}$ & $\begin{array}{c}\mathbf{2 . 8} \text { to } \\
<\mathbf{7 . 8}\end{array}$ & $\begin{array}{c}\mathbf{7 . 8} \text { to } \\
\mathbf{1 1 . 1}\end{array}$ & $\mathbf{> 1 1 . 1}$ & Total \\
\hline $\begin{array}{c}\text { ingestion of fizzy drink } \\
\text { in the last 2 hrs }\end{array}$ & yes & 0 & 76 & 14 & 5 & 95 \\
\hline & no & 2 & 449 & 52 & 7 & 510 \\
\hline Total & & 2 & 525 & 66 & 12 & 605 \\
\hline
\end{tabular}

Of the 442 patients who presented within 7 days of their illnesses, 2(0.5\%) had hypoglycemia, 369(83.5\%) were euglycaemic, 59(13.3\%) had Hyperglycemia and 12(2.7\%) had profound Hyperglycemia compared to $0(0 \%), 156(95.7 \%), 7(4.3 \%)$ 
and $0(0 \%)$ who had hypoglycemia, euglycaemia, Hyperglycemia and profound Hyperglycemia respectively of the 163 patients who has been ill for more than 7 days before presentation (Table 5). The difference is statistically significant $\left(x^{2}=16.161 ; p=0.001\right)$.

Table 5: Cross tabulation of RBG level against duration of illness $\left(x^{2}=16.161 ; p=0.001\right)$.

\begin{tabular}{|c|c|c|c|c|c|}
\hline \multicolumn{5}{|c|}{ Random Blood Glucose Grading (mmol/L) } \\
\hline & $<\mathbf{2 . 8}$ & $\mathbf{2 . 8}$ to $<\mathbf{7 . 8}$ & $\mathbf{7 . 8}$ to $\mathbf{1 1 . 1}$ & $>\mathbf{1 1 . 1}$ & 12 \\
\hline Duration $\leq 7$ & 2 & 369 & 59 & 0 & 442 \\
\hline of illness (days)>7 & 0 & 156 & 7 & 12 & 163 \\
\hline Total & 2 & 525 & 66 & 605 \\
\hline
\end{tabular}

Logistic regression was done using independent variables like sex, age, RBG, duration of illness, and ingestion of fizzy drink against outcome (whether or not patient was admitted). Only duration of illness and RBG level was found to be predictive of whether or not patient will be admitted into children emergency ward from the children outpatient department ( $p=0.001$ and $0.000 ; \beta$ coefficient 0.399 and 0.277 respectively). The other factors (age and sex,) were not predictive of outcome; they had p value $>0.05$ (Table 6).

Table 6: Predictors of outcome of children presenting in children outpatient of EKSUTH.

\begin{tabular}{|c|c|c|c|c|}
\hline Variables & Categories of variables & $\mathbf{P}$ & $\begin{array}{c}\text { OR } \\
\text { ( } \beta \text { Coefficient) }\end{array}$ & $95 \% \mathrm{CI}$ \\
\hline Age group & Less than 5years (ref) & 0.855 & 0.959 & 0.614-1.498 \\
\hline Sex & Male (ref) & 0.502 & 0.866 & $0.569-1.318$ \\
\hline Random blood glucose & Dysglycaemia (ref) & $<0.001$ & 0.277 & $0.166-0.460$ \\
\hline Duration of illness & Less than 7 days (ref) & 0.001 & 0.399 & $0.228-0.697$ \\
\hline
\end{tabular}

\section{Discussion}

Disorder of glucose metabolism is well documented in studies among acutely ill children and adults admitted into emergency or intensive care units within and outside Africa [1-12]. There are no known published studies of disorder of glucose disorder among ill children seen in Children Out-Patient Department (COPD). The index study therefore sought to document pattern of random blood glucose among children seen in the COPD of Ekiti State University Teaching Hospital (EKSUTH), Nigeria. A total of 605 children were seen during the 5 months study period and duration of illness ranged from few hours to 365days. Four hundred and forty three $(73.2 \%)$ of the 605 studied children were treated and followed up on outpatient basis; $132(21.8 \%)$ were admitted into children emergency ward while $30(5 \%)$ were referred to other specialties like Surgery. The four commonest presentations at COPD of EKSUTH were respiratory tract infection (23.5\%), malaria (22\%), gastroenteritis $(12.4 \%)$ and skin rashes $(9.4 \%)$ as shown in Table 3. This is comparable to presentations at Komfo Anokye Teaching Hospital, Kumasi, Ghana [7] and in Lagos University Teaching Hospital, Nigeria [10] where severe malaria, diarrhea and vomiting, acute respiratory tract infections, and septicaemia were the 4 commonest presentations. Understandably, uncomplicated respiratory tract infection, malaria and diarrhea with vomiting were the commonest in the index study because it was done among children seen on out-patient basis compared to those seen among children admitted to emergency wards.

Hypoglycemia in the index study is very low $0.3 \%$ compared to $3.1 \%, 5.6 \%, 6.5 \%$ and $7.7 \%$ in studies among admitted critically ill children in Madagascar [11], Nigeria(Lagos) [10], Ghana [7], and Mozambique [2]. The low incidence of hypoglycemia among children seen in out-patient department can be explained by the less severe nature of illnesses among children presenting in COPD compared to those admitted into children emergency ward. Also, children presenting in out-patient departments would have been offered one fizzy drink or the other, however little, helping to maintain their blood glucose and preventing hypoglycemia. The few ones who were hypoglycemic were too ill to accept any food or drink and were admitted into children emergency ward for management. None of the children given fizzy drinks within 2 hours of RBG check had hypoglycemia compared to $0.4 \%$ of those not given fizzy drinks who developed hypoglycemia. This may lend credence to the importance of giving glucose containing fluids, including oral rehydration salt, to ill children who are refusing household diet until they are able to accept regular diet in order to prevent hypoglycemia.

The proportion of children with Hyperglycemia in the index study was $12.9 \%$. This is low compared to $43.5 \%$ among admitted sick Ghanaian children [7] and 15.9\% among Mozambique children [2]. The study among Mozambique children was conducted mainly on children with severe malaria. Consumption of glucose by $\mathrm{P}$ falciparum coupled with reduced oral intake by patients with severe malaria may have mitigated against the expected hyperglycaemia induced by stress of severe illnesses [2,5,13,14]. Hyperglycemia in the index study among children seen on out-patient basis can be partly explained by high glucose content of various fizzy drinks offered the ill children to pacify or to encourage them to take their medication. Also, stress-induced gluconeogenesis will play a significant role though not as much as would be expected in critically ill children admitted into intensive care units. Twenty 
percent of the children who were given fizzy drinks in the index study had transient Hyperglycemia compared to $11.3 \%$ of those who were not offered fizzy drink. All the children who had Hyperglycemia eventually had normal fasting blood glucose and none was diabetic. There is need for moderation in administration of fizzy drinks to pacify ill children as this can greatly distort their glucose metabolism and may put them at higher risk of developing diabetes later in life $[3,4]$.

Normal blood glucose was recorded in $86.6 \%$ of children seen in COPD and this is higher than 50\% and 74\% normal RBG recorded among critically ill children admitted into emergency wards in Ghana and Mozambique respectively [7,2]. Children seen on outpatient basis were able to maintain normal blood glucose because of ability to take in food and drinks, however little, compared to the critically ill children who most often are not able to tolerate orally. The ability of majority of children to maintain normal blood glucose during mild illness should help to reassure parents and care-givers that their children will be able to cope very well if they present early for appropriate treatment on out-patient basis. Those who are having acute watery diarrhea should continue to administer oral rehydration salt until the diarrhea subsides.

Dysglycaemia was significantly more prominent in children with acute illnesses who presented within 7 days of onset of their illnesses compared to those whose illnesses has been on for more than 7 days before presentation. This may be due to higher levels of circulating mediators of stress like glucagon, cortisol, and adrenalin during the first few days of acute illness [3]. The effects of these mediators on glucose metabolism wear off with time and the body develops tolerance hence low frequency of dysglycaemia in chronic illnesses. Our finding suggests that recognition of dysglycaemia in children presenting in COPD can be improved as this may help in giving prompt attention to those that need urgent medical assistance. It will also serve as screening for prediabetes and diabetes in children and adolescents. Previous study at EKSUTH [15] showed that $100 \%$ of children with type 1 diabetes presented in emergency (diabetic ketoacidosis) compared to some developed countries where less than $50 \%$ of their diabetic children presented in emergency [16,17]. Children with illnesses less than 7 days duration and those with dysglycaemia should be properly assessed and followed up as shown in the index study that these are predictive of those that will be admitted among those that presented in Children outpatient department.

\section{Conclusion}

Transient hyperglycaemia is relatively common among acutely ill children seen in the Children Out-Patient Department of EKSUTH, though majority of them were able to maintain normal blood glucose with or without ingestion of fizzy drinks. Duration of illness less than 7days and dysglycaemia were highly predictive of patients who were admitted into emergency ward from the Children outpatient department of EKSUTH.

\section{Acknowledgement}

We sincerely appreciate the cooperation and contribution of the patients and their parents, the nurses, house officers and registrars in the Department of Pediatrics, EKSUTH, Ado-Ekiti in making this study feasible.

\section{References}

1. Matz k, Keresztes K, Tatschl C, Nowotny M, Dachenhausen A, et al. (2006) Disorder of glucose metabolism in acute stroke patients: an unrecognized problem. Diabetes Care 29(4): 792-797.

2. Madrid L, Sitoe A, Varo R, Nhampossa T, Lanaspa M, et al. (2017) Continuous determination of blood glucose in children admitted with malaria in a rural hospital in Mozambique. Malaria journal 16(1):184.

3. Gornik l, Vujaklija-Brajkovic A, Renar IP, Gasparovic V (2010) A prospective observational study of the relationship of critical illness associated hyperglycaemia in medical ICU patients and subsequent development of type 2 diabetes. Crit Care 14(4): R130.

4. Gornik I, Vujaklija A, Lukic E, Madzarac G, Gasporavic V (2010) Hyperglycaemia in critical illness is a risk factor for later development of type II diabetes mellitus. Acta Diabetol suppl 1: 29-33.

5. Madrid L, Lanaspa M, Maculuve SA, Bassat Q (2015) Malaria-associated hypoglycaemia in children. Expert Rev Anti Infect Ther 13(2): 267-277.

6. Kawo NG, Msengi AE, Swai AB, Chuwa LM, Alberti KG, McLarty DG, et al. (1990) Hypoglycaemia and cerebral malaria. Lancet 336: 1128-1129.

7. Ameyaw E, Amponsah-Achiano K, Yamoah P, Chanoine JP (2014) Abnormal blood glucose as a prognostic factor for adverse clinical outcome in children admitted to the Paediatric emergency unit at Komfo Anokye Teaching Hospital, Kumasi, Ghana. International Journal of Pediatrics 2014(2014): 149070.

8. Davidson UN, Chikee AE, Chukwuebuka NO (2017) Relationship between Hypoglycemia and Home Remedies among Critically Ill Children in a Developing Country: An Undisclosed Danger. Ann Med Health Sci Res 7: 185-189.

9. Palacio A, Ceron M, Klein R, Cho IS, Smiley D, et al. (2008) Prevalence and clinical outcome of inpatient hyperglycaemia in a Community Pediatric Hospital. J Hosp Med 3(3): 212-217.

10. Oyenusi EE, Oduwole AO, Oladipo O0, Njokanma OF, Esezobor CI (2014) Hypoglycaemia in children aged 1 month to 10 years admitted to the Children emergency Centre of Lagos University Teaching Hospital, Nigeria. S Afr J CH 8(3): 107-111.

11. Sambany E, Pussard E, Rajaonarivo C, Raobijaona H, Barennes H. Childhood Dysglycemia: Prevalence and Outcome in a Referral Hospital. Plos One 2013; 8(5): e65193.

12. Altibas V, Altibas K, Berkovic-Cigrovski M, Malosevac S, Vrkljan M, Heitzler VN (2012) Glucose metabolism disorders in patients with acute coronary syndromes. Acta Clin Croat 51(1):71-73.

13. Kawo NG, Msengi AE, Swai AB, Chuwa LM, Alberti KG, et al. (1990) Hypoglycaemia and cerebral malaria. Lancet 336(8723): 1128-1129.

14. White NJ, Warrell DA, Chanthavanich P, Looareesuwan S, Warrell MJ, et al. (1983) Severe hypoglycemia and hyperinsulinemia in falciparum malaria. N Engl J Med 309: 61-66.

15. Oluwayemi IO, Taiwo AF, Ayeni TO (2017) Eight year review of Paediatric endocrine cases seen in Ekiti State University Teaching Hospital. Indian journal of Applied Research 7(7): 506-507.

16. Habib HS (2005) Frequency of ketoacidosis in newly diagnosed type 1 diabetes mellitus in Northwest Saudi Arabia. Saudi Med J 26(12):19361939.

17. Abdul Rasoul M, Al Mahdl M, Al Quttan H, Al Tarkait N, Alhkouly M, et al. (2010) Ketoacidosis at presentation of type 1 diabetes in children in Kuwait: frequency and clinical characteristics. Pediatr Diabetes 11(5): 351-356. 
Creative Commons Attribution 4.0

International License

For possible submissions Click Here
Submit Article
Your subsequent submission with Crimson Publishers will attain the below benefits

- High-level peer review and editorial services

- Freely accessible online immediately upon publication

- Authors retain the copyright to their work

- Licensing it under a Creative Commons license

- Visibility through different online platforms

- Global attainment for your research

- Article availability in different formats (Pdf, E-pub, Full Text)

- Endless customer service

- Reasonable Membership services

- Reprints availability upon request

- One step article tracking system 